\title{
Un retrato del escultor Juan Sanmartín y Serna, obra del pintor madrileño José Alarcón (1886)
}

\author{
A portrait of the sculptor Juan Sanmartín y Serna, \\ painted by José Alarcón (1886), a painter from Madrid \\ JOSÉ MANUEL GARCÍA IGLESIAS \\ josemanuel.garcia.iglesias@usc.es \\ https://orcid.org/0000-0003-0491-3213 \\ http://dx.doi.org/10.15304/sm.31.5951
}

\section{RESUMEN}

La Real Sociedad Económica de Amigos del País de la Ciudad de Santiago cuenta con un retrato del escultor Juan Sanmartín Serna, realizado en Madrid, en el año 1886, por el pintor José Alarcón. Guarda ciertos paralelismos, posiblemente pretendidos, con el del también escultor Felipe de Castro, obra de Gregorio Ferro. En el caso del de Sanmartín se hace referencia a su arte a través de un Cervantes en prisión, escultura suya que iba a presentar a la Exposición Nacional de 1887.

Hoy esta pintura puede verse en el primer piso de la Facultad de Geografía e Historia de la Universidad de Santiago, en su lado oriental, formando parte de un conjunto de obras depositadas, en tal lugar, por la Real Sociedad Económica de Amigos del País de la ciudad de Santiago.

Palabras clave: Juan Sanmartín y Serna, José Alarcón, Cervantes en prisión, Exposición Nacional de 1887, Real Sociedad Económica de Amigos del País de la Ciudad de Santiago.

\section{Abstract}

The Royal Economic Society of Friends of the Country of Santiago has a portrait of the sculptor Juan Sanmartín y Serna, painted by José Alarcón in 1886. This portrait keeps parallelism, probably pretended, with the one of the sculptor Felipe de Castro, painted by Gregorio Ferro. In the case of Sanmartín`s portrait we can find references to his art through the image of his sculpture of Cervantes in prison, sculpture which he was going to present in the National Exhibition in 1887.

Today, this picture can be seen in the first floor of the Geography and History School of the University of Santiago, in its oriental side, being part of a set of works of art placed there by the Royal Economic Society of Friends of the Country of Santiago.

Keywords: Juan Sanmartín y Serna, José Alarcón, Cervantes in prison, National Exhibition of 1887, Royal Economic Society of Friends of the Country of Santiago 


\section{ANTE UNA PINTURA}

El retrato que nos muestra al escultor Juan Sanmartín y Serna -así es como se le denomina en el expediente que se conserva en el Archivo de la Real Sociedad Económica de la Ciudad de Santiago (Fernández Casanova, 1961)- (Santiago de Compostela, 18301898) lo presenta en pie, con su mano derecha oculta por su ropa y la otra posada sobre un voluminoso libro que se localiza sobre una mesa de formas barrocas. En un segundo plano puede verse una librería ante la que se encuentra una carpeta repleta de láminas y, también, sobre un alto pedestal, una escultura suya: Cervantes en prisión, que iba a presentar a la Exposición Nacional de Madrid de 1887; ésta es la razón por la que el pintor, José Alarcón, la incorpora a este retrato de 1886; se trata, en definitiva, de una obra con la que el escultor pretende consagrarse en la capital de España (fig.1).

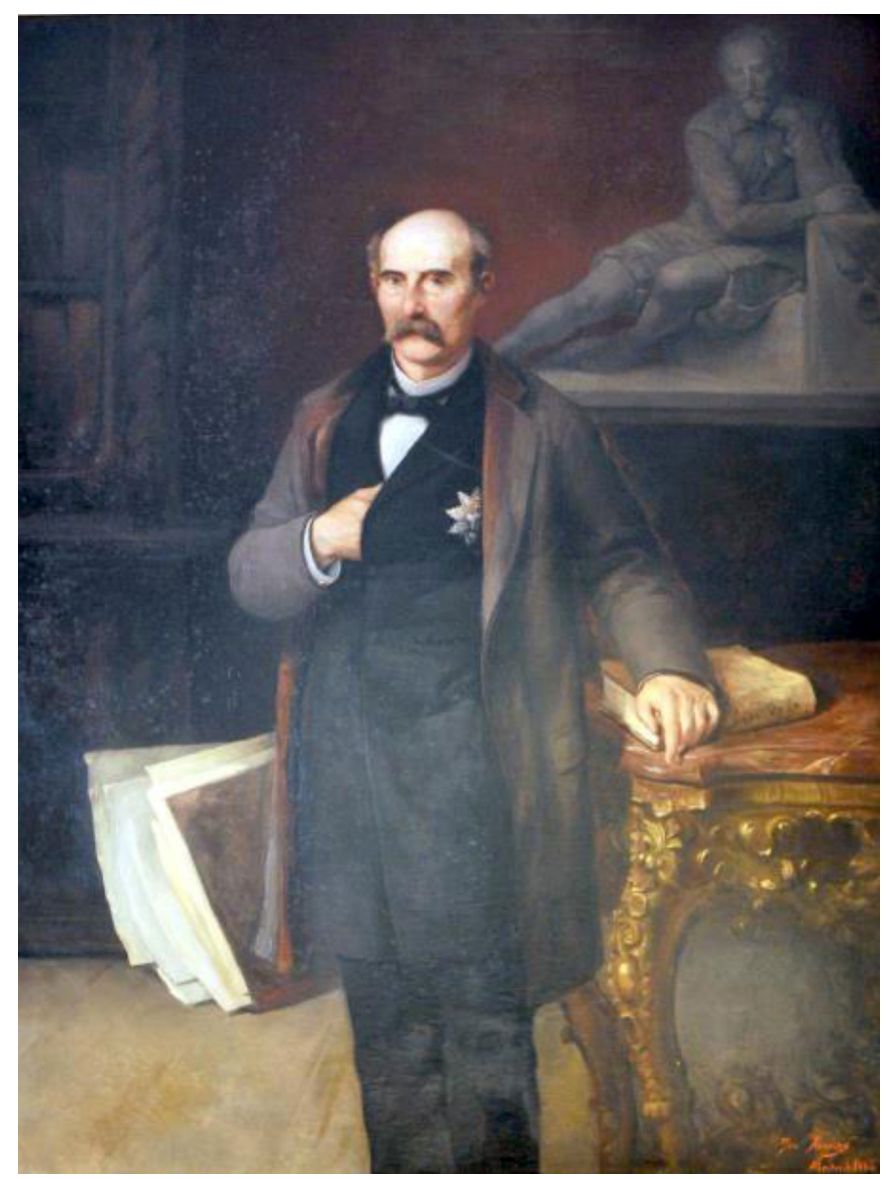

Figura 1. Juan Sanmartín, obra de José Alarcón. Real Sociedad Económica de Amigos del País de la Ciudad de Santiago. Facultad de Geografía e Historia de la USC. 
Que exista un retrato dedicado a este escultor entre los pertenecientes a la Real Sociedad Económica de Amigos del País de la ciudad de Santiago no resulta ilógico dada su relación con esta entidad compostelana a partir de 1859, año en el que es nombrado profesor de Dibujo. Extraña, en cambio, el lugar en el que fue hecho, Madrid, y su tamaño, muy superior al de los propios presidentes de la Económica. El hecho de que fuese donado por Alarcón, para “un nuevo Museo”, y la supuesta relación de éste con el retratado, explican el resultado final.

\section{EL RETRATADO}

Contó este artista compostelano, en sus primeros años, con estancias en Ferrol, trabajando en los talleres del Arsenal, y A Coruña, formándose en talleres de imaginería. Gracias al mecenazgo, primero, de Luis López Ballesteros, ministro de Hacienda de Fernando VII y, después del hijo de éste, Nicolás, pudo ingresar en la Academia de San Fernando de Madrid asistiendo al taller de José Piquer i Duart, Director de Escultura de dicha Academia, incardinado en el estilo romántico.

Por dos veces estuvo en Italia, particularmente en Roma. En 1863, casi un año; y en 1870, en una estancia que se va a alargar hasta 1882 lo cual no significa que, en algún momento concreto, por ejemplo, en 1872, estuviese algún tiempo en Compostela. Con motivo de su primera visita fue nombrado miembro de las academias de San Lucas, en Roma y de Bellas Artes de Carrara.

Su relación con la Real Sociedad Económica de Amigos del País de Santiago es importante. según se desprende de su expediente personal como socio de esta entidad, $\mathrm{Su}$ labor docente se desarrolla entre 1859 y 1868; entonces, renuncia, "por motivos de salud" a dicha ocupación. Y ya desde 1861, a propuesta de Eugenio Montero Ríos, se le otorga el honor de ser Socio de Mérito; se acepta poniendo en valor la ejecución de su estatua relativa al padre Feijoo, imagen destinada a la Biblioteca Nacional, modelada en yeso y hoy desparecida (Martínez Porto, 2004: 321).

En 1871, ahora a propuesta del Director de la Económica, Maximino Teijeiro, se le otorga el título de Director Honorario de la Escuela de Dibujo y Modelado de la Sociedad Económica, aludiéndose a que es el encargado "de los trabajos de la estatua del ilustre gallego Excmo. Sr. D. Casto Méndez Núñez”; era Sanmartín un escultor apreciado por este director; dan cuenta de ello dos medallones, con retratos de perfil de Maximino Teijeiro (fig. 2) y de su mujer, María Reales (fig. 3), que se datan por 1869 y que pertenecen, también, a esta entidad (Martínez Porto, 2004: 322, 328-329).

Consta la asistencia de Sanmartín a distintas sesiones de la Económica: once, en 1868; una en 1869; dos en 1870; una en 1872; una en 1886; siete en 1888; dos en 1889; dos en 1890; tres en 1891; una en 1892; tres en 1893; tres en 1894; dos en 1895; y una en 1896. En ese año, 1896, también se da cuenta de que Sanmartín "regaló para 
la kermesse organizada por la Económica y celebrada durante las fiestas de Julio, un Atlas de Geografía Antigua". Hay constancia, finalmente, ya en 1898, de su muerte, el 11 de octubre ${ }^{1}$.

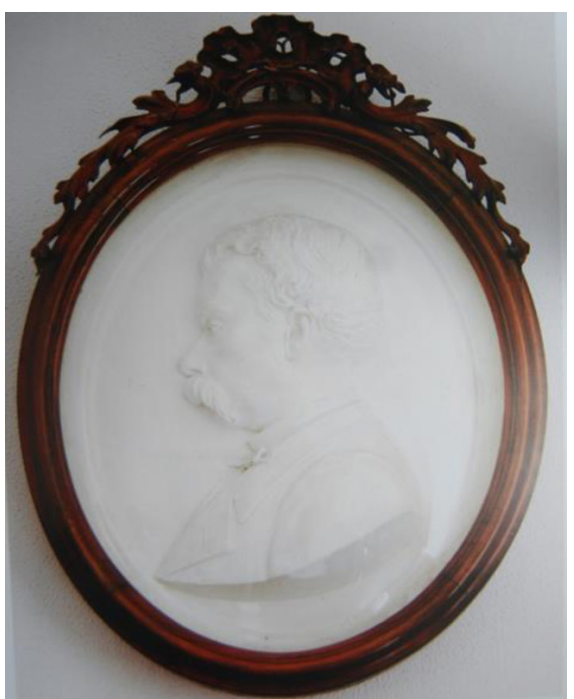

Figura 2. Medallón de Maximino Teijeiro. Juan Sanmartín. Real Sociedad Económica de Amigos del País. Santiago de Compostela Fotografía: Xulio Gil

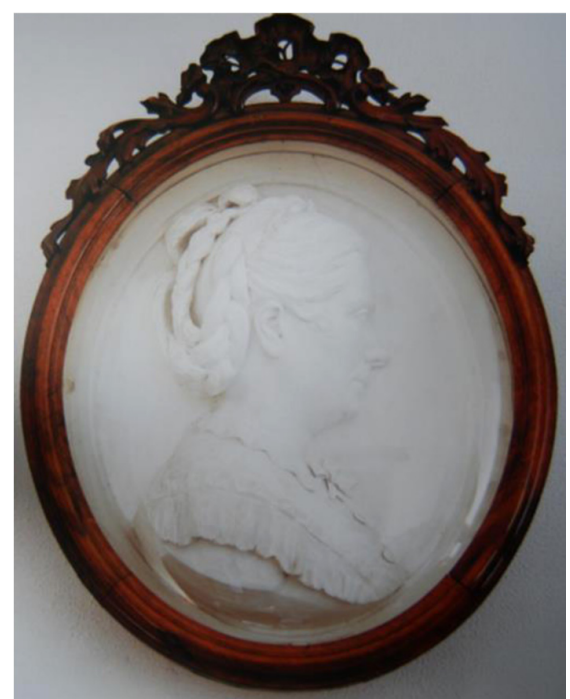

Figura 3. Medallón de María Reales. Juan Sanmartín. Real Sociedad Económica de Amigos del País. Santiago de Compostela Fotografía: Xulio Gil

Su labor decente, después de 1886, se va a centrar ya en la Escuela de Artes y Oficios de Santiago, en donde va a ser su primer profesor de Modelado y Vaciado (Sousa y Pereira, 1988: 143). También, por estas fechas, se hace cargo de la plaza de escultor anatómico de la Facultad de Medicina, lo que le vincula a la Universidad de Santiago; en este sentido cabe decir que se contaba, por entonces, con un buen Museo Anatómico ero éste se valía de escuetas asignaciones presupuestarias (García Guerra, 2001: 193).

Son dos las obras compostelanas por los que es especialmente conocido: el paso procesional de la Santa Cena, contratado en 1863 (fig. 4), y la estatua del almirante Casto Méndez Núñez, sita en la Alameda, obra de la que se responsabiliza a partir de 1871 y que tendrá un largo proceso de gestación hasta que se dispone, por 1885, en el lugar que ocupa (fig. 5). Fue el ayuntamiento compostelano quien le encargó ambos trabajos. También responde a su autoría las imágenes de San Francisco de Sales y de San Vicente de Paul que pueden verse en la iglesia das Orfas (Martínez Porto, 2004: 326, 338-339). 


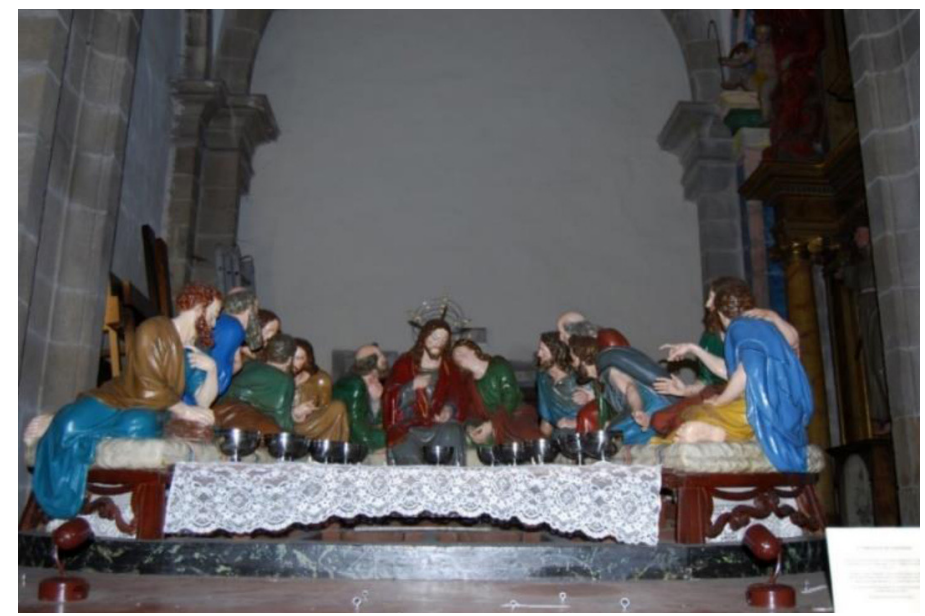

Figura 4. Santa Cena.

Juan Sanmartín. Iglesia de San Francisco. Santiago de Compostela.

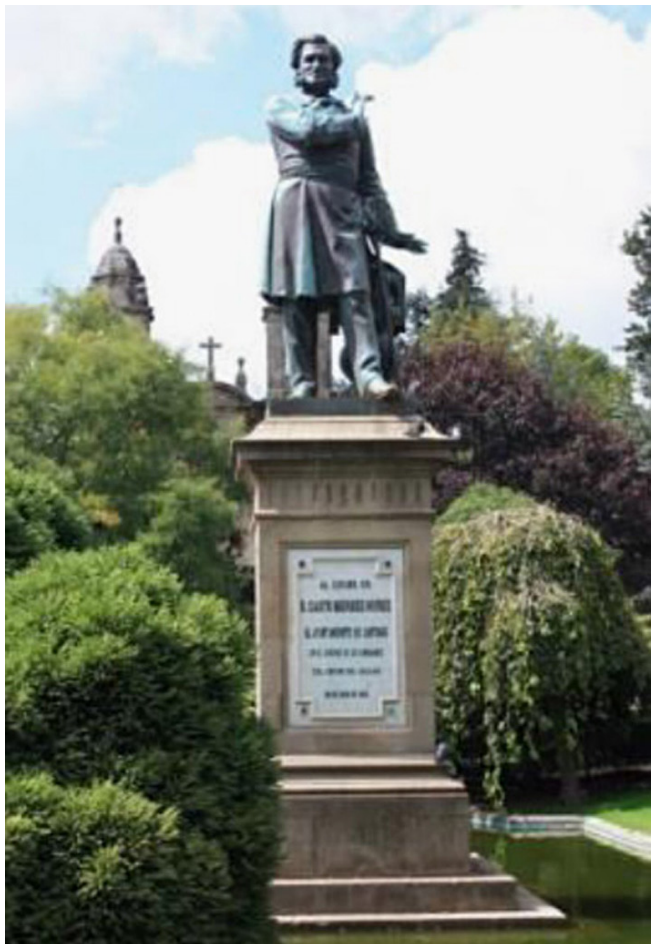

Figura 5. El Almirante Méndez Núñez.

Juan Sanmartín. Alameda. Santiago de Compostela

En: http://memoriasdecompostela.blogspot.com/2011/09/ estatua-de-mendez-nunez-1885.html 
Con motivo de su estancia italiana de 1863 fue nombrado miembro de las academias de San Lucas, en Roma, y de Carrara; y, en relación con su segundo paso por esta ciudad, y dadas las obras allí hechas, se le otorgó el título de Profesor Honorario de la Real Academia de Bellas Artes de Carrara. Consiguió, también, menciones honoríficas en las Exposiciones Nacionales de 1858 y 1863. En 1867 recibió una pensión de la Diputación Provincial de Pontevedra para ir a la Exposición Universal de París de ese año. Fue distinguido con la Cruz de Isabel la Católica y, en virtud de sus obras relativas a marinos -fundamentalmente, sus estatuas dedicadas a Cristóbal Colón; también, la de Méndez Núñez-, recibió la Gran Cruz de la Orden del Mérito Naval y, además, los reconocimientos de las cruces de Cristo de Portugal y Carlos III, algo que ha sido ya reconocido en su propio tiempo (Barreiro de Vázquez Varela, 1884: 275-276, 282; Ovilo y Otero, 1884: 144-150; Cirvigo y Vorga, 1885: 4-5) y, también, en la actualidad (López Vázquez, 1993: 186-187; Martínez Porto, 2004: 320-327).

\section{EL RETRATISTA}

La cuestión primera es distinguir si el José Alarcón que firma el cuadro es José María Alarcón y Cárceles. (Murcia, 1848-Madrid 1904) o José Alarcón y Suarez, natural de Madrid. Ambos cuentan con obras relativamente parecidas, con quehacer en Madrid por la misma época y que se han formado, respectivamente, en la Academia de Bellas Artes de Murcia y en la de San Fernando. El costumbrismo era el género en el que habitualmente se desarrolla su obra. Se afirma que mientras el primero firmaba "J. Alarcón”, el segundo tendía a poner "Alarcón Suarez" y "A. Suarez". En este caso nos encontramos con una firma diferente dado que pone su nombre completo "José", con el apellido "Alarcón" al lado; además alude al lugar en el que lo ha pintado "Madrid" y la fecha en que se hizo: 1886.

Hay, también, en este mismo tiempo otros dos pintores de apellido Alarcón, de nombres Felix, natural de Andalucía, y Julia, residente en Valencia (Ossorio y Bernard, 1883-1884: 16).

Cabe considerar que estamos ante un cuadro que, muy probablemente, fue encargado y, en cierta medida, orientado por el propio Juan Sanmartín quien bien pudo tener una cierta amistad con quien le retrata. A nuestro modo de ver se trata de José Alarcón y Suárez, pintor que, además del tema costumbrista, cuenta con un buen número de retratos y de paisajes; es un artista activo en el Madrid del último tercio del siglo XIX; también él, de forma previa, se había ocupado del tema cervantino; concretamente había presentado a la Exposición Nacional de 1871 un cuadro titulado El retablo de Maese Pedro (Ossorio y Bernard, 1883-1884: 16).

2 Vid. http://wm1640482.web-maker.es/BIOGRAF-AS-DE-PINTORES-A/Jose- Mar-a-AlarconCarceles/ 
Es este José Alarcón quien, en definitiva, va a donar, sin duda por sugerencia del propio Sanmartín, la obra a la Económica; hay constancia de ello a través de un escrito suyo, fechado en Madrid el 8 de Mayo de 1887, en el que se indica la ubicación de su estudio en la calle de San Agustín no 3 . Con el objeto de dar un mayor empaque a la humilde hoja, cuadriculada, de papel que utiliza lo cuña, en la parte superior, "Círculo de Bellas Artes". Está dirigida la misiva al "Exmo Sor. Presidente de la Sociedad de Amigos del País". Y dice lo siguiente:

\begin{abstract}
"Muy señor mío y de mi más distinguida consideración: tengo el honor de participarle que tiempo ha pinté al óleo un retrato del célebre escultor D. Juan Sanmartín hijo de esa noble tierra. Como quiera que se ha fundado en esa un nuevo Museo bajo el patrocinio de esa digna corporación, yo me vería muy honrado si mi modesta obra figurase en sus galerías; para cuyo efecto, Sr. Director, la ofrezco sin retribución alguna, si mereciese los honores de ser recibida. Aguardando su favorable contestación, quedo a a sus órdenes su S. S. Q.B.S.M" Y firma "José Alarcón".
\end{abstract}

En ese mismo escrito, en la parte inferior, se testimonia la aceptación del siguiente modo:

“Sesión del 25 de Mayo de 1887. En la de este día se acordó admitir el ofrecimiento y darle las más expresivas gracias por su generoso donativo autorizando a la Dirección para disponer lo necesario a cerca de la admisión de dicho retrato. El Vicesecretario Salvador Cabeza"3.

Se trata de Salvador Cabeza de León quien firma esta aceptación y es Joaquín Díaz de Rábago quien preside, por entonces, la Económica.

En muestra de gratitud, y previo informe de una comisión nombrada al respecto, la Sociedad Económica distinguió a este pintor nombrándole socio de mérito, "la mayor distinción que está en su mano ofrecer", honor que acepta, agradecido, y que es acreditado enviándole un diploma, así como los estatutos correspondientes. Por cierto, figura Manuel Murguía entre los miembros de esa comisión-

\title{
4. EL RETRATO
}

Quien se encargó de retirar del taller del pintor esta pintura fue don Pedro Calderón y Herce, "Senador por esta Sociedad Económica". Vino este cuadro a Galicia siendo "facturado a la estación de Curtis".

La Comisión que, en la Sociedad Económica, evalúa el regalo recibido, eleva un acta en la que se dice:

3 Archivo de la Real Sociedad Caja 128.7. 


\begin{abstract}
"Reunida en el local del Museo, donde dicho cuadro se halla colocado y habiéndolo examinado detenidamente y encontrado que por su bello colorido, buen dibujo y exacto parecido, es un regalo digno de la Sociedad y que puede figurar entre los mejores cuadros de su Museo"
\end{abstract}

Y, también, alaba el "bello marco dorado" que lo encuadra.

Estamos ante un retrato que bien puede tener como referencia, en el pensamiento de Sanmartín, el del también escultor Felipe de Castro, obra de Gregorio Ferro (fig. 6), que podía verse, por entonces, en la Biblioteca Pública de Santiago, en la Universidad (vid. García Iglesias, 2016, 182-186). Resulta algo lógico si se tiene en cuenta que, en su propio tiempo, se establecieron similitudes entre ambos escultores, en cuestiones tales como su experiencia italiana (Cirvigo y Vorga,1885: 4). En lo básico los dos cuadros contienen los mismos motivos: la figura en tres cuartos, en un ambiente en el que lo manual de su arte se combina con el mundo del libro, significativo del estudio; con una vestimenta distinguida y acompañados, como fondo de la pintura, de obra suya; en el caso de Felipe de Castro, el busto del Padre Sarmiento; en el de Sanmartín, la citada imagen de Cervantes en prisión. De ella se ha dicho:

\begin{abstract}
"El escritor suele aparecer con gesto abatido, privado de libertad, lo que contrasta con la grandeza del proceso creativo, que tiene lugar en unas condiciones de aislamiento y adversidad. Se asemeja a un mártir que padece por una causa superior en la que cree, aunque todavía no haya triunfado. Encarna la idea romántica del individualismo y de la necesidad de persistir en el ideal frente a la miseria moral de los ignorantes" (Reyero Hermosilla, 2016: 147).
\end{abstract}

Además, para el retrato de Sanmartín se opta por un tamaño próximo (166 x $126 \mathrm{cms}$.) al que Gregorio Ferro había utilizado para pintar a Felipe de Castro (220 x155 cms.).

¿Qué posibles fuentes de inspiración pudo tener Sanmartín para hacer "su" Cervantes? Es más que

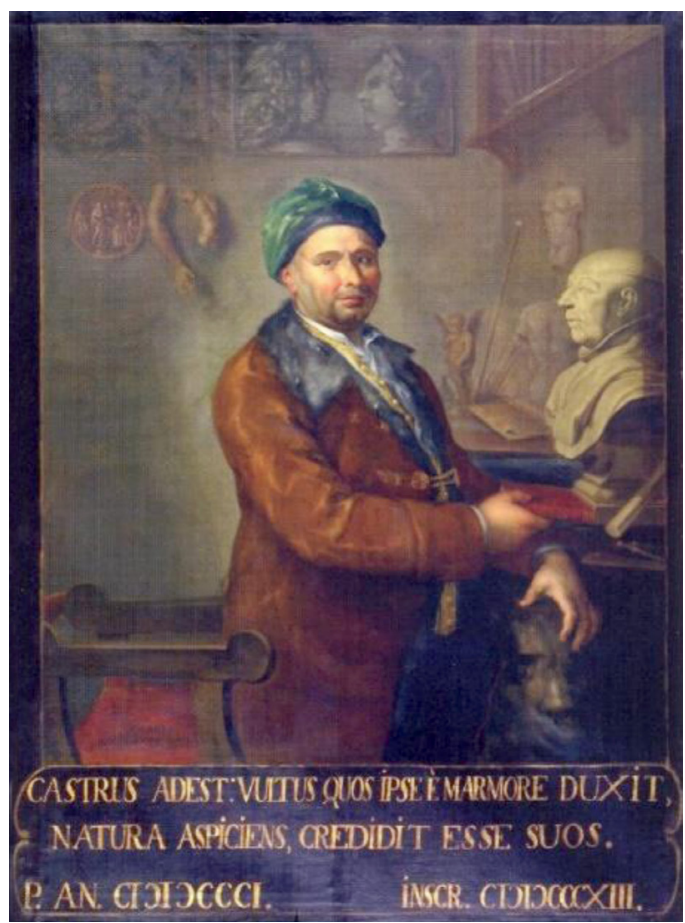

Figura 6. Felipe de Castro.

Gregorio Ferro. Sala de Profesores de la Facultad de Xeografía e Historia.

Santiago de Compostela. 
probable, por la cercanía que hay entre ambas obras, que conociese y partiese de una lámina integrada en una edición de El ingenioso hidalgo Don Quijote de la Mancha, publicada en Madrid, por Biblioteca Universal Ilustrada en el año 1877. Sus doce láminas responden a grabados que firma "V. Barneto" (Vicente Barneto y Vázquez) y han sido estampadas por "Estab. tip. de J.A. Muñoz"4; un texto que nos dice Miguel de Cervantes, imaginando El Quijote pretende dar sentido a la imagen, en este caso (fig. 7).

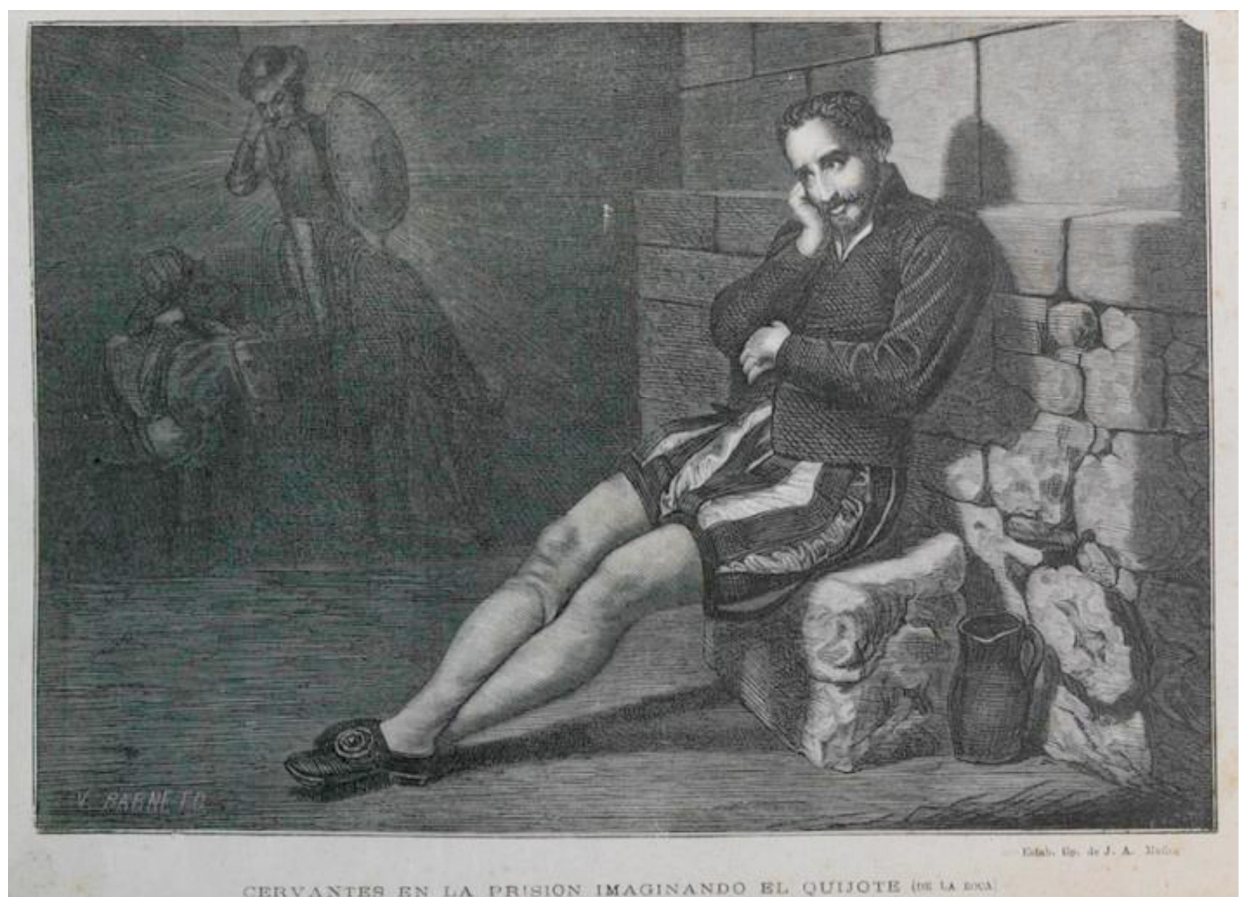

Figura 7. Cervantes en prisión imaginando el Quijote. Grabado de V. Barneto" (Vicente Barneto y Vázquez), estampado por "Estab. tip. de J.A. Muñoz". En M. de Cervantes, El ingenioso hidalgo Don Quijote de la Mancha, Madrid, Biblioteca Universal Ilustrada, 1877.

En https://www.flickr.com/photos/fdctsevilla/26072948893

En realidad estamos ante un grabado que parte, de forma bien fidedigna, de una pintura de Mariano de la Roca y Delgado, que se titula igual (fig. 8), realizada en 1858 (171x210 cms.); esta representación había conseguido la tercera medalla en la Exposición Nacional de 1858; pertenece, actualmente, a los fondos del Museo del Prado 5 .

4 Vid. https://www.flickr.com/photos/fdctsevilla/26072948893

5 Vid. https://www.museodelprado.es/coleccion/obra-de-arte/miguel-de- cervantes-imaginando-elquijote/c914bb74-d296-4487-bdcd- 6c528bc6b3df 


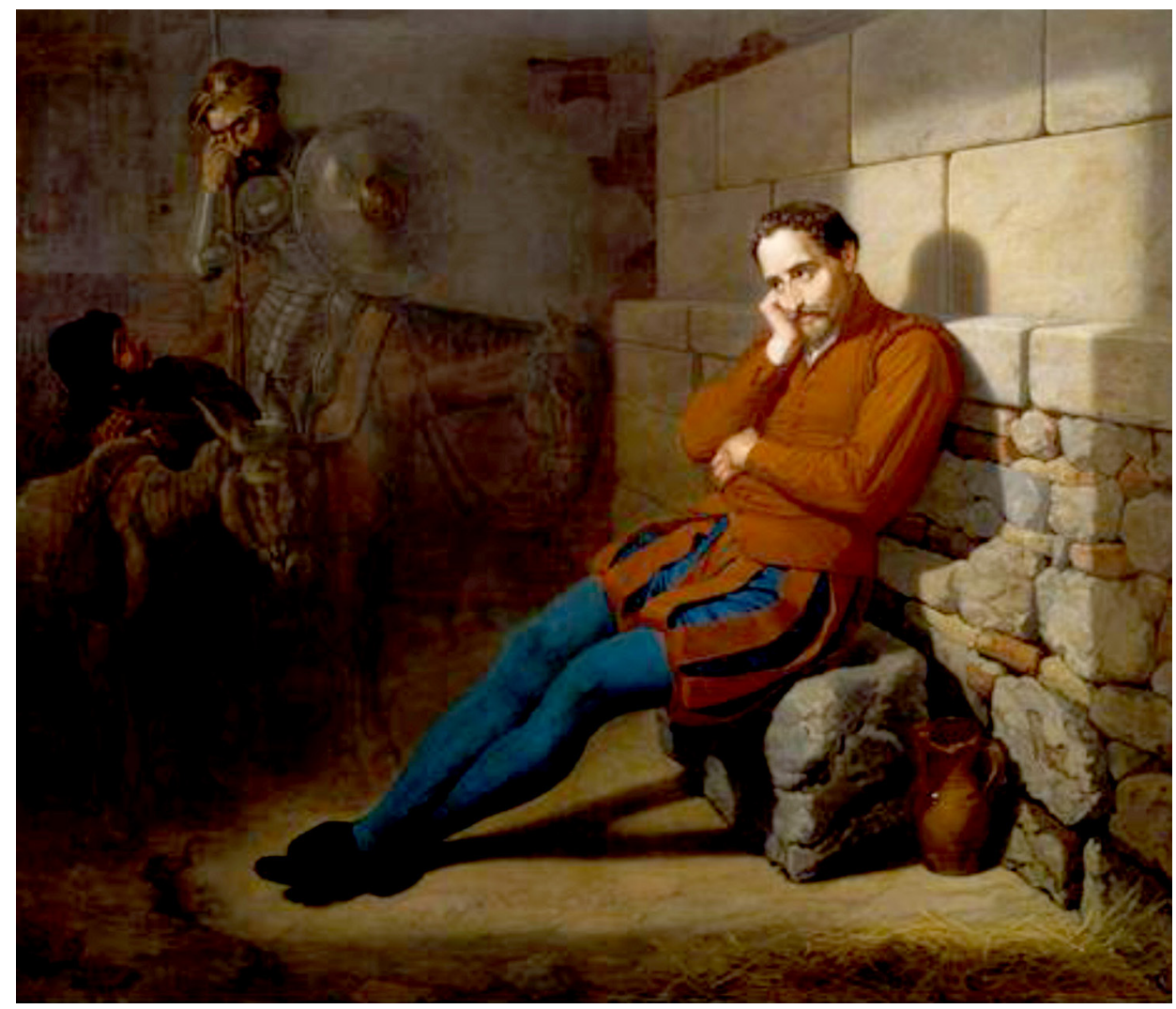

Figura 8. Miguel de Cervantes, imaginando El Quijote

Mariano de la Roca y Delgado, 1858 (171x210 cms). Tercera medalla en la Exposición Nacional de 1858. Museo del Prado.

En (https://www.museodelprado.es/coleccion/obra-de-arte/miguel-de-cervantes-imaginando-el-quijote/c914 bb74-d296-4487-bdcd-6c528bc6b3df

La representación de esta escultura de Sanmartin, hoy en paradero desconocido, se conoce gracias a una fotografía, que la muestra en la citada Exposición Nacional: una obra en yeso, bien cuidada; dicha fotografía es de J. Laurent, del año 1887 y pertenece al Archivo Ruiz Vernacci (fig. 9), depositado en la Fototeca del Patrimonio Histórico Español ${ }^{6}$; fue publicada por Reyero (Reyero Hermosilla, 2016: 147).

Lo que hace Sanmartín, en su interpretación del tema, en relación con ese punto de partida, fue tomar de la estampa lo fundamental; es decir, la figura de Cervantes, con una fisonomía y una vestimenta determinada, partiendo de la posición de sus brazos, también,

6 Vid. http://www.mcu.es/fototeca_patrimonio/Visor?usarVisorMCU=true\&archi vo=RUIZ $\% 20$ VERNACCI/preview/VN-01522_P.jpg 
aunque invirtiendo el orden de los mismos: el derecho toma la forma del izquierdo y viceversa; es decir, como si en vez de copiar, en este sentido, el grabado propiamente dicho se hiciese desde la plancha desde la que se concibió el grabado original. Por otra parte, al no contar con la pared de la prisión para apoyar al personaje lo adelanta, manteniendo, desde su posición sentada, su cabeza, meditabundo, sobre su brazo izquierdo en tanto que, en la derecha, sostiene, en este caso, una pluma, dispuesto ya a escribir. Y es que, si Sanmartín opta por una escritura en ciernes, los antecedentes, pintado y grabado, nos muestran, en cambio, a un Cervantes imaginativo, participando de ese ambiente carcelario la presencia del Quijote y Sancho, lo que lleva al escritor a esbozar una cierta sonrisa.

Pero volvamos al modo en que se presenta en este retrato al escultor. Debe de tenerse, por otra parte, en cuenta la relación a establecer entre Juan de Sanmartín y Felipe de Castro. El haber hecho Sanmartín, para la villa de Noia, una estatua en recuerdo de Felipe de Castro, después de su vuelta de Italia, en 1882, le aproximó a este personaje y, ya en el modo de concebir su cabeza, se puede ver su inspiración en el citado retrato que le había

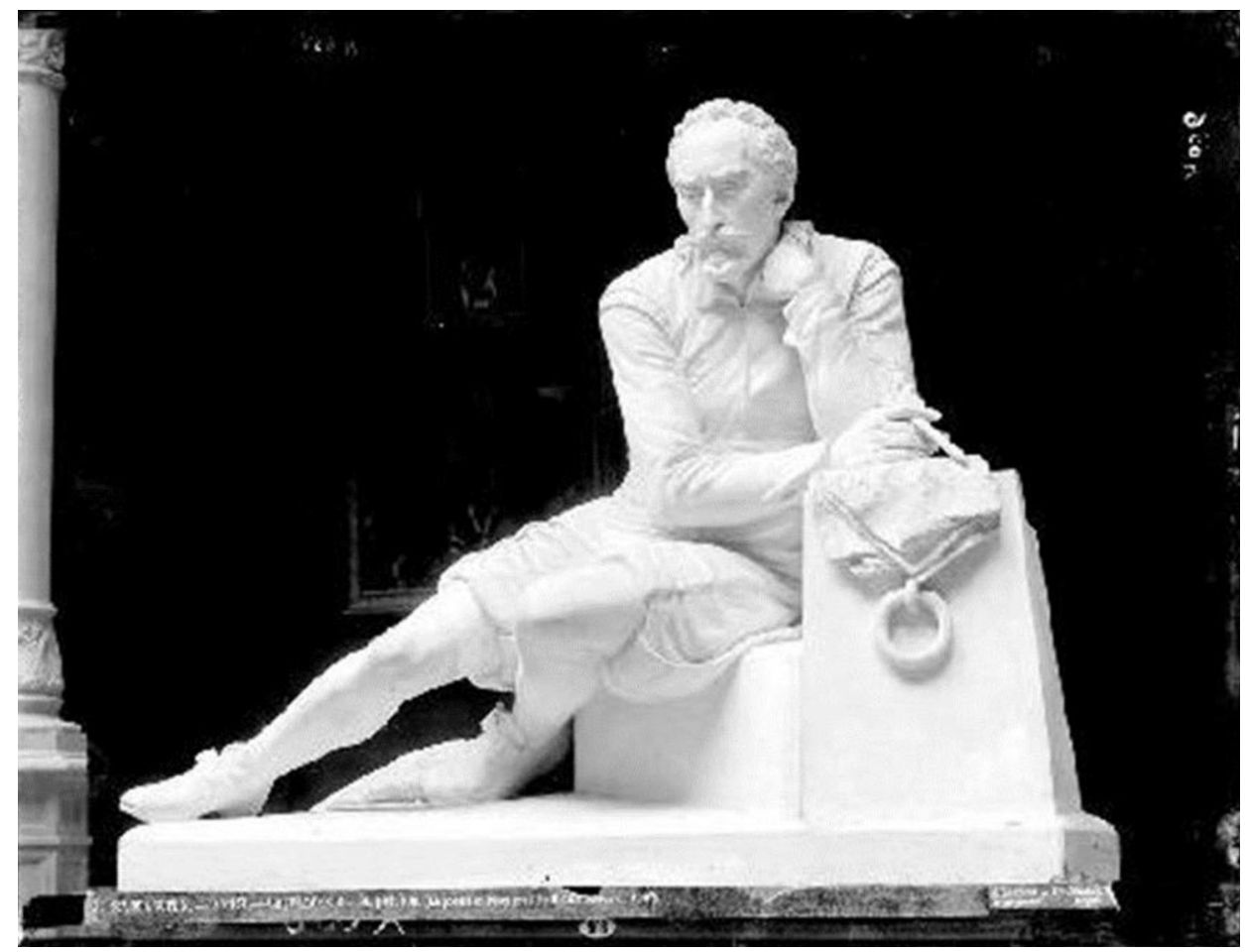

Figura 9. Cervantes en la prisión

Escultura en yeso de Juan Sanmartín, 1886. Presentada a la Exposición Nacional de 1887.

Fotografía de J. Laurent, del año 1887.

Archivo Ruiz Vernacci, depositada en la Fototeca del Patrimonio Histórico Español

En (http://www.mcu.es/fototeca_patrimonio/Visor?usarVisorMCU=true\&archivo=RUIZ\%20VERNACCI/preview/VN-01522_P.jpg) 
hecho Gregorio Ferro (Martínez Porto, 2004: 326). Noya le reconoció, en recompensa por el busto hecho, con la distinción de hijo adoptivo; hizo este trabajo, por encargo de Romero Ortiz, sin percibir nada a cambio (Ovilo y Otero, 1884: 150). Por cierto, también a Sanmartín, en el retrato de Alarcón, le preocupa el modo en que se presenta ante nosotros, elegante y con la Gran Cruz de la Orden del Mérito Naval en el pecho (Fernández Castiñeiras, Monterroso Montero, Ariarte, 2010: 134).

Se podría decir, también, que, como apunta López Vázquez en el concerniente a Felipe de Castro, que estamos ante un "retrato perfecto", en el sentido, siguiendo a Lavatier, de que "muestra la mente humana con las peculiaridades del carácter de la persona" (López Vázquez,1993: 128). El pintor nos aproxima al gesto serio de una cabeza ya vieja, parecida a la de un cuadro de este autor (fig. 10) que guardan los fondos del Museo del $\mathrm{Prado}^{7}$; prácticamente calvo, con algunas arrugas, grandes mostachos y el gesto adusto.

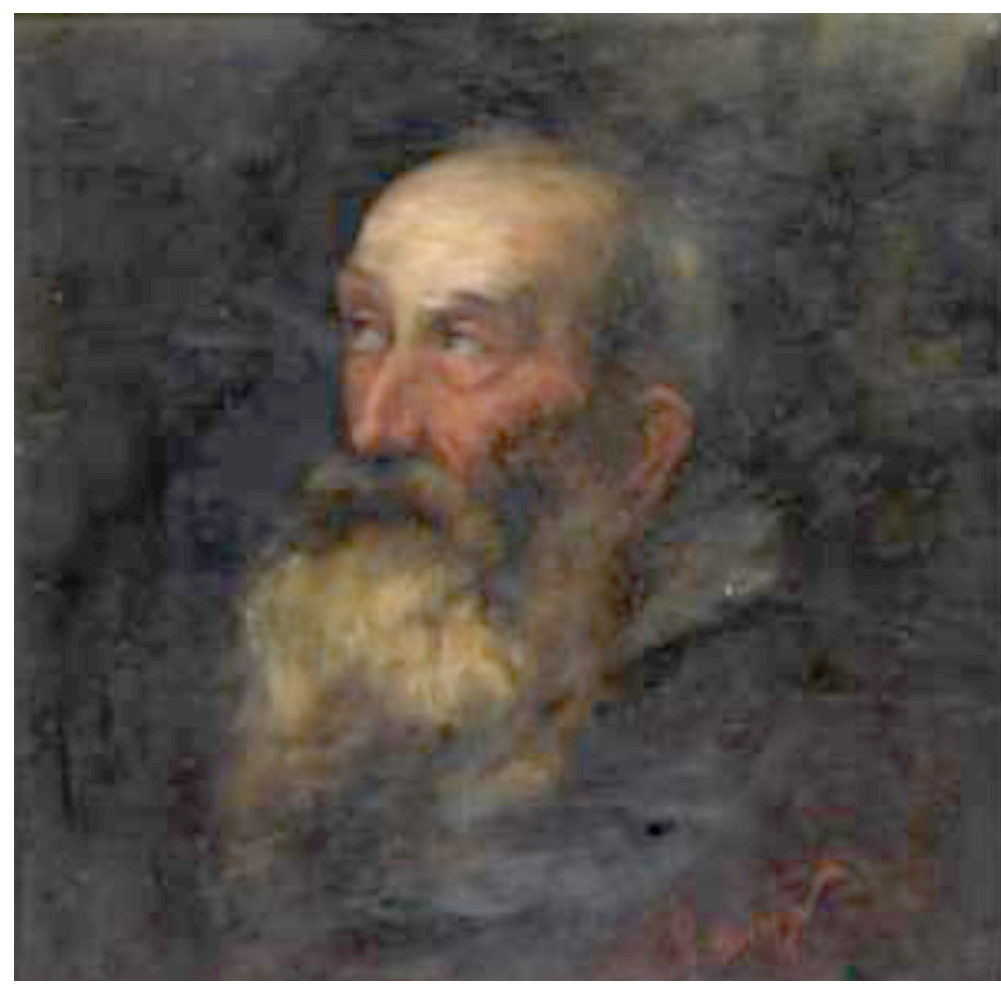

Figura 10. Cabeza de viejo. José Alarcón Museo del Prado. Madrid. En https:/www.museodelprado.es/coleccion/artista/alarcon-jose/14a72290-453a-42d5afeb-a36a3f61e91e

7 Vid. https://www.museodelprado.es/coleccion/artista/alarcon-jose/14a72290-453a-42d5-afeba36a3f61e91e 
Una cuestión a relacionar, en este caso, con la forma de trabajar de este pintor: el modo en que dispone y hace las manos. En un catálogo, titulado "Pintura Antigua", de Isbilya Subastas (Sevilla), puede verse una "Joven con guitarra y mantón” (fig. 11), en óleo sobre lienzo, firmado "J. Alarcón” (100 x 66 cms.), con un modo de considerar las manos similar: la derecha, oculta bajo la ropa; la otra apoyada, de una manera muy parecida a la que puede verse en el retrato de Sanmartín ${ }^{8}$.

Merece, también, un comentario la firma. No es habitual, en este pintor, que diga el lugar en que pinta (en este caso, Madrid); quizás lo haga para dar cuenta de su relación con ese personaje en ese lugar. Y tampoco es común que, en vez de poner su inicial, J., desarrolle su nombre completo, José ¿hay, en ello, un indicio de proximidad entre retratista y retratado? La fecha enumerada, 1886, también resulta significati-

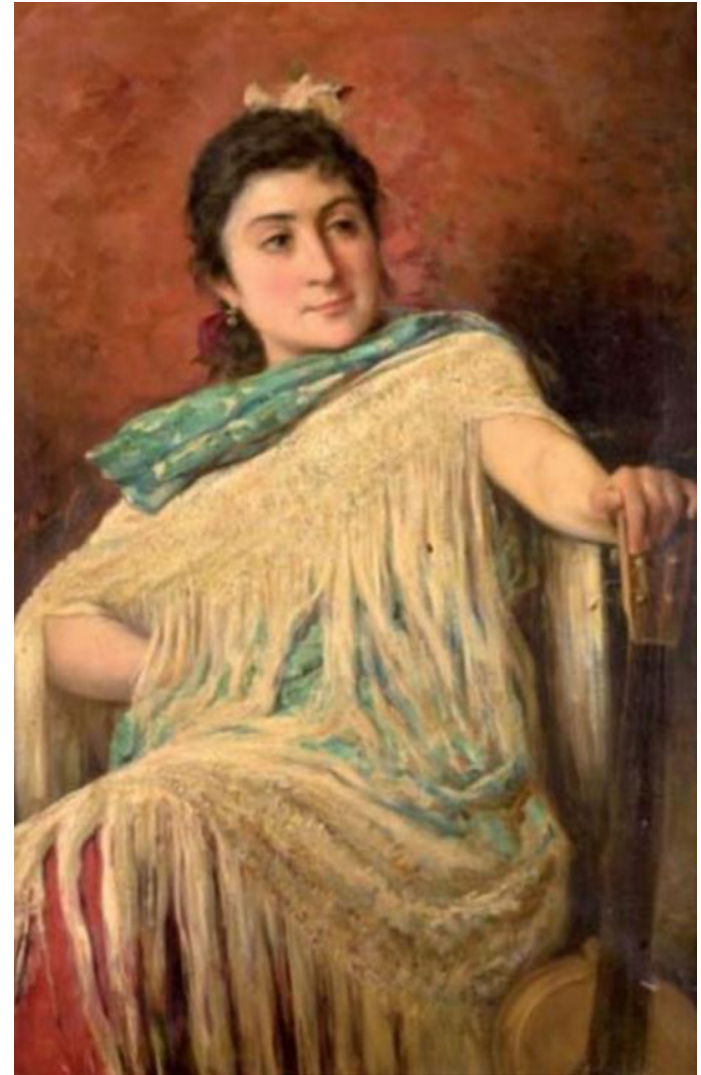

Figura 11. "Joven con guitarra y mantón" Óleo sobre lienzo J. Alarcón" (100 x 66 cm).

En https://www.isbilyasubastas.com/catalogos/2016/03/ sesion_1_p_antigua.pdf va; estamos un año antes de la Exposición Nacional a la que Sanmartín presenta su Cervantes en prisión y entiende que esa obra lo identifica y, en cierta medida, lo engrandece; al fin y al cabo se trataba de mostrar plásticamente a un escritor muy relevante, como lo había hecho, también, Gregorio Ferro en el caso de presentarnos, con Felipe de Castro, al padre Sarmiento. Por otra parte, en esos tiempos, la figura de Miguel de Cervantes había sido reconocida especialmente en la Compostela (fig. 12) en la que vive, de tal manera que se le dedica a él, también, con una escultura el centro de una fuente en una de las plazas de la ciudad que, a partir de esos momentos, llevará su nombre (García Iglesias, 2016: 235-237). 
Figura 12. Miguel de Cervantes Plaza de Cervantes. Santiago de Compostela

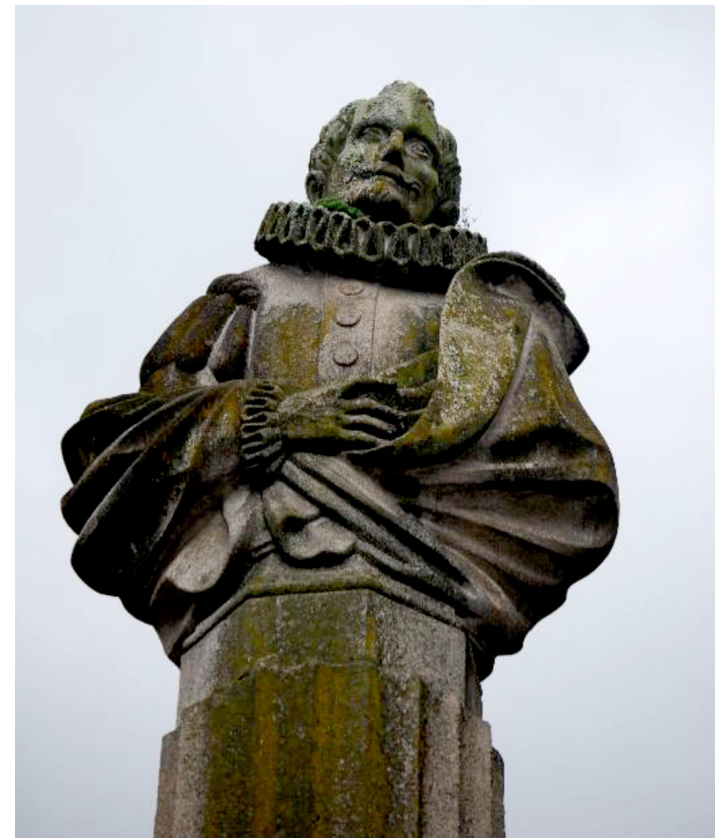

\section{A DÍA DE HOY}

La pintura va y viene. Incluso la de las instancias que cabe considerar más estables como pueden ser la Universidad de Santiago o la Real Sociedad Económica de Amigos del País de la Ciudad de Santiago, ambas varias veces centenarias. Y el retrato de Felipe de Castro, que nació para estar en una biblioteca, hoy se encuentra en la sala de profesores de la Facultad de Xeografía e Historia, en la misma planta del edificio para la que fue concebido pero, obviamente, en un espacio, y en una ambientación, diferente.

Las circunstancias hicieron que aquel otro retrato, que muy posiblemente, Sanmartín encargó emulando al de un escultor de referencia, y al que admiraba, terminase por ser de la Económica, sociedad que lo había distinguido, previamente con la condición de Socio de Mérito y de Director Honorario de la Escuela de Dibujo y Modelado. Por las circunstancias propias de una institución que cambió varias veces de sede el cuadro anduvo de un lugar para otro hasta que, por falta de espacio, quedó almacenado. Hoy, gracias a un acuerdo entre la Universidad de Santiago y la Real Sociedad Económica, suscrito en el año 2017, el retrato de Sanmartín se encuentra en la actual Facultad de Xeografía e Historia, en Compostela, en uno de los laterales del claustro, en su ala oriental, en el primer nivel del mismo edificio; cercano, de tal modo, al de Felipe de Castro, a la vista de todo aquel que transita ante las aulas, como un viejo profesor que trabajó, también él, en esta Universidad, en su ya citada condición de haber sido escultor anatómico de la Facultad de Medicina. 


\section{BIBLIOGRAFÍA}

Barreiro de Vázquez Varela, B. (1884): "El Escultor gallego D. Juan Sanmartín y Serna", Galicia diplomática, II, 37, pp. 275-276, II, 38, p. 282.

Cirvigo y Vorga, A. (1885). "Juan Sanmartín y Serna”, Año 1, n 9, pp. 4-5.

Fernández Casanova, M.C. (1961). La Sociedad Económica de Amigos del País de Santiago en el siglo XIX, Edicións do Castro, Sada ( A Coruña).

Fernández Castiñeiras, E, Monterroso Montero, J.M. y Ariarte, S. C. (2010). Real Sociedad Económica de Amigos del País de la ciudad de Santiago. Catálogo ose fondos pictóricos, Santiago de Compostela, Real Sociedad Económica de Amigos del País de la ciudad de Santiago.

García Guerra, D. (2001). La Facultad de Medicina de Santiago en el siglo XIX, Santiago de Compostela, Universidad de Santiago.

García Iglesias, J.M. (2016). Minerva la diosa de Compostela. Espacios y obras a relacionar con el saber, Santiago de Compostela Andavira Editora, Consorcio de Santiago.

López Vázquez, J.M. (1993). “Neoclásico.- Do Neoclásico a 1950”, en J. M. López Vázquez, I. Seara Morales, Arte Contemporánea, T. XV, A Coruña, Hércules Ediciones, pp. 28-319.

Martínez Porto, D. (2004). “Juan Sanmartín”, en A. Pulido Novoa (dir.), Artistas Galegos escultores. Séculos XVIII e XIX, Vigo, Nova Galicia Edicións S. L., pp. 318-339.

Ossorio y Bernard, M. (1883-1884). Galería biográfica de artistas españoles del siglo XIX, Madrid, Imprenta de Moreno y Rojas.

Ovilo y Otero, M. (1884). "Don Juan Sanmartín de la Serna”, Escenas contemporáneas, IV, 35 (1884), pp. 144-150.

Reyero Hermosilla, C. (2016). "La fortuna visual de Cervantes”, en J. M. Lucía Megías (coord.), Miguel de Cervantes: de la vida al mito (1616-2016), Madrid. Biblioteca Nacional de España, pp. 139-165). En http://cervantes.bne.es/ficheros/exposicion/ ESTUDIOS/03_La_fortuna_visual_de_cervantez.pdf

Sousa, J. y Pereira, F. (1988). Historia de la Escuela de Artes y Oficios de Santiago de Compostela, A Coruña, Diputación Provincial. 